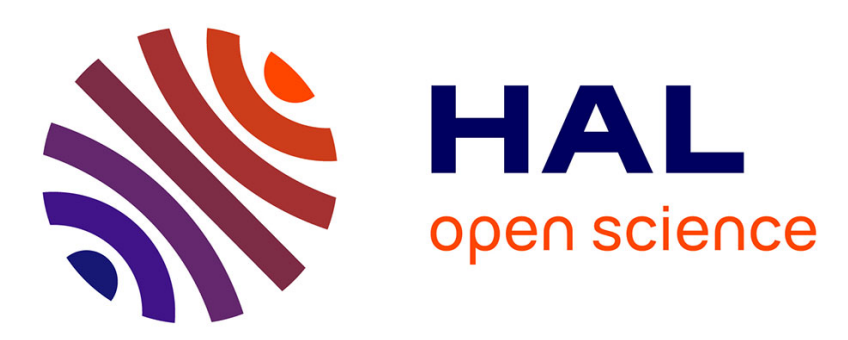

\title{
Experimental and numerical studies of pulverized coal devolatilization and oxidation in strained methane/air flames
}

Meng Xia, Diego Zabrodiec, Philippe Scouflaire, Benoît Fiorina, Nasser

Darabiha

\section{To cite this version:}

Meng Xia, Diego Zabrodiec, Philippe Scouflaire, Benoît Fiorina, Nasser Darabiha. Experimental and numerical studies of pulverized coal devolatilization and oxidation in strained methane/air flames. Proceedings of the Combustion Institute, 2017, 36 (2), pp.2123 - 2130. 10.1016/j.proci.2016.07.080 . hal-01542060

\section{HAL Id: hal-01542060 \\ https://hal.science/hal-01542060}

Submitted on 6 Apr 2020

HAL is a multi-disciplinary open access archive for the deposit and dissemination of scientific research documents, whether they are published or not. The documents may come from teaching and research institutions in France or abroad, or from public or private research centers.
L'archive ouverte pluridisciplinaire HAL, est destinée au dépôt et à la diffusion de documents scientifiques de niveau recherche, publiés ou non, émanant des établissements d'enseignement et de recherche français ou étrangers, des laboratoires publics ou privés. 


\title{
Experimental and numerical studies of pulverized coal devolatilization and oxidation in strained methane/air flames
}

\author{
Meng Xia*, Diego Zabrodiec ${ }^{1}$, Philippe Scouflaire, Benoît Fiorina, \\ Nasser Darabiha
}

Laboratoire EM2C, CNRS, CentraleSupélec, Université Paris-Saclay, Châtenay-Malabry, France

\begin{abstract}
Experimental and numerical investigations of the combustion of a methane/air mixture fed with coal particles are performed. The retained configuration is a laminar 1-D strained flame impinging a wall. The wall surface promotes the formation of a methane/air flame front parallel to the stagnation plane. Coal particles oxidation takes place in the hot region between the flame front and the wall. Laser induced fluorescence PLIF measurements of $\mathrm{OH}$ radical and imaging of $\mathrm{CH}^{*}, \mathrm{C}_{2}^{*}$ spontaneous emission are performed to identify the chemical flame structure. The inlet fresh gas boundary conditions are well characterized in the experiments in terms of gas velocity but also number of coal particles and mean particle diameter. These conditions are used to perform numerical simulations with the 1-D REGATH code developed at EM2C laboratory. The governing equations are fully coupled between gas and particle phase. Detailed chemical kinetics based on USC-Mech II reaction scheme, $\mathrm{NO}_{x}$ chemistry and $\mathrm{OH}^{*} / \mathrm{CH}^{*} / \mathrm{C}_{2}^{*}$ sub-mechanisms are considered. The numerical predictions showed good agreement with the experimental data. The analysis of obtained results confirmed that the composition of volatile species of coal has a significant influence on the $\mathrm{CH}^{*}$ and $\mathrm{C}_{2}^{*}$ concentration in the post-flame region. Finally, the effects of volatile matter composition, strain rate and particle size on the $\mathrm{NO}_{x}, \mathrm{C}_{2} \mathrm{H}_{2}$ and $\mathrm{C}_{6} \mathrm{H}_{6}$ formation are studied.
\end{abstract}

\section{Introduction}

Coal has been and will continue to be one of the most important resources in the long term due to its abundant worldwide reserves and competitively low prices, especially used in the power generation [1]. However, with the growing demand of more reliable and cleaner energy supply, pollutants such 
as $\mathrm{NO}_{x}$, unburned hydrocarbons ( $\mathrm{HC}$ ) and soot, emitted during coal combustion are one of the key issues in global air pollution. Hence, effectively reducing pollution from coal combustion, especially from those with low rank coal, is significant to limit greenhouse gases and respect air pollutant emission standards.

Coal combustion is a complex phenomenon that involves devolatilization, gasification and both volumetric and surface chemical reactions. In order to characterize the behavior of pulverized coal flames such as the flame structure, stability, burnout and pollutant formation, both experimental techniques and numerical simulations are essential to get a better understanding of these physical and chemical processes. In particular, the gas phase reaction of coal volatile matter is an extremely important process that controls the behaviors of pulverized coal combustion [2]. Xu and Tomita [3,4] studied experimentally the pyrolysis of different ranks of coals in an inert atmosphere. The pyrolysis products were classified into inorganic gases $\left(\mathrm{H}_{2}, \mathrm{CO}_{2}, \mathrm{CO}\right.$, and $\mathrm{H}_{2} \mathrm{O}$ ), hydrocarbon gases (C1-C3), light hydrocarbon liquids (benzene, toluene, xylene, phenol and cresol) and tar. The yields of different species depend significantly on the coal type as well as pyrolysis temperature.

Entrained flow reactors, such as flat flame burners, were used in several studies [5-7] to investigate the effect of coal devolatilization and gasification in a preheated unstrained laminar flow under air and oxy-combustion conditions. Optical pyrometry and particle image velocimetry (PIV) as well as char and burnt gases composition measurements were carried out. Coal devolatilization and char oxidation sub-models able to predict the product composition in this configuration have been validated $[7,8]$. Experimental studies [9-11] have been also conducted on pulverized coal jet flame structure using $\mathrm{OH}$ planar laser-induced fluorescence (OH PLIF). Balusamy et al. [11] investigated the effect of oxidizer/diluent concentrations and coal loading rate.

The LES simulation performed by Muto et al. [12] successfully predicted the characteristics of Balusamy configuration [11]. Another well-studied setup is the CRIEPI jet flame burner [10] and several validations of LES modeling were conducted and showed good results [13]. In these simulations, the volatile matter is modeled as mono-species, i.e. $\mathrm{C}_{x} \mathrm{H}_{y} \mathrm{O}_{z}[12,13]$ or only $\mathrm{CH}_{4}$ [14] using global reaction schemes for reducing computational cost. Although the results show a good accordance with velocity statistics and temperature profiles, the predictions of species concentration are qualitative.

Whilst devolatilization and gasification submodels are involved in LES/RANS simulations of pulverized coal turbulent flames, their impact on the flame structure and prediction of pollutants still remains unknown. According to Peters [15],

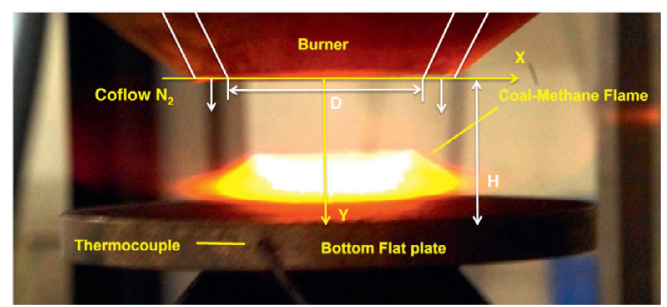

Fig. 1. Direct view of coal/methane/air flame.

instantaneous flame element embedded in a turbulent flow has the structure of a 1-D strained laminar flame. This elemental configuration, retained in many studies on gaseous $[16,17]$ or two-phase flow flames $[18,19]$ is attractive to understand such fundamental coal combustion properties.

The objective of the present work is to study experimentally and numerically the combustion of pulverized coal in a mixture of methane/air reactive flow and to investigate the impact of coal pyrolysis sub-models on flame structure and pollutant formation. A laboratory-scale laminar strained configuration is designed. The configuration is a premixed methane/air flow that impacts on a wall surface. The pulverized coal conveyed by the flow reacts in the hot region confined between the methane-air flame front and the wall. Spontaneous emission of $\mathrm{CH}^{*}$ and $\mathrm{C}_{2}^{*}$ as well as LIF of $\mathrm{OH}$ spectrum are experimentally measured across the jet axis. Numerical analyses are performed by implementing kinetic models of pulverized coal combustion in the 1-D REGATH code developed at EM2C laboratory. The coal particles are simulated by devolatilization and gasification reactions, coupling with the gas phase calculated with a detailed chemical reaction scheme for the methane-air combustion [20]. The validity of modeling is assessed by comparing the experimental and numerical results of $\mathrm{OH}, \mathrm{CH}^{*}$ and $\mathrm{C}_{2}^{*}$ radicals. The effects of gasphase volatile reactions on the flame structure and pollutant formation, including unburned hydrocarbons, $\mathrm{NO}_{x}$ and soot precursor such as $\mathrm{C}_{2} \mathrm{H}_{2}, \mathrm{C}_{6} \mathrm{H}_{6}$ are examined in detail.

\section{Experimental configurations}

\subsection{Experimental setup}

The experiments were carried out using a strained flow burner shown in Fig. 1. Additional details are found in $[16,19]$. The convergent nozzle is axisymmetric and has an inner diameter of $10 \mathrm{~mm}$. Pulverized coal particles are carried by premixed methane/air flow at ambient pressure and temperature, which then impacts a horizontal metallic brass wall. In this paper, the distance between the nozzle and the wall is kept constant to $10 \mathrm{~mm}$. A coaxial nozzle fed by nitrogen 
creates an inert coflow, which protects the reaction zone from ambient perturbations that could disturb the measurements. The flow impacting the wall forms a strained flow. A laminar flame front stabilizes at a distance from the wall, which depends on the laminar flame speed and the injection velocity. The hot gases from the methane/air combustion are located between the flame front and the wall. Pulverized coal particles are heated in this hot region. Figure 1 shows a direct view of the coal/methane/air flame. The high luminosity is only observed in coal-seeded flames.

\subsection{Diagnostic techniques}

PLIF measurements of $\mathrm{OH}$ radical are performed. The laser used for the PLIF is a tunable Dye laser (using Rhodamine 590 as a lasing medium) pumped by a $\mathrm{Nd}$ :Yag pulsed laser at $532 \mathrm{~nm}$. A frequency doubling unit is mounted at the exit of the Dye Laser in order to reach the wavelength of $283.09 \mathrm{~nm}$ which corresponds to the Q1(6) rotational branch from the $\mathrm{OH}$ transition system. The duration of the laser pulse is $10 \mathrm{~ns}$ with the power of $18 \mathrm{~mJ}$ per pulse. An ICCD camera of $1024 \times 1024$ pixel detector is used with a Nikon UV-Nikor $105 \mathrm{~mm}$. The planar laser sheet is aligned with the jet axis and includes the flame reaction zone. The $\mathrm{OH}$ Narrow-band filter is centered at $313 \mathrm{~nm}$, which has $10 \mathrm{~nm}$ bandpass and 68\% transmission in the maximum. The $\mathrm{OH}$ profiles are corrected with the laser sheet energy profile on a single shot basis. An average of over 200 OH PLIF images is done. From the averaged images, the relative concentration profiles are obtained from the pixels values at the jet axis. The scale in the resulting measurements represents pure fluorescence intensity, and does not directly correspond to $\mathrm{OH}$ mole fraction because the LIF signals are not corrected for quenching, the thermal distribution and saturation effects. However it has been observed that quenching effects on the OH PLIF signals are constant. The OH LIF signals can therefore be considered linearly proportional to the $\mathrm{OH}$ radical population within a calibration constant.

Direct view images of $\mathrm{CH}^{*}$ and $\mathrm{C}_{2}^{*}$ spontaneous emission have also been recorded using the same camera and optics used for the PLIF. Emission profiles are obtained by averaging 200 images. The uncertainty of measurements corresponds to the RMS of the signals captured by the camera and is less than $5 \%$ in all experiments. The images are corrected by means of dark background subtraction. Narrow-band interference filters are interposed along the optical path for capturing the $\mathrm{CH}^{*}$ emission. The filter used has $60 \%$ transmission and a $10 \mathrm{~nm}$ wide bandpass centered around $430 \mathrm{~nm}$. The filter for $\mathrm{C}_{2}^{*}$ bandpass is centered around $516.5 \mathrm{~nm}$ and has $10 \mathrm{~nm}$ bandwidth. The spatial resolution obtained by the optical arrangements is $0.1 \mathrm{~mm}$.

\subsection{Experimental cases studied}

Two experimental flame configurations, named case METH and case METH-COAL, are performed with and without the injection of coal particles, respectively. For both flames, the equivalence ratio of the carrying methane/air stream is characterized by an injection temperature of $310 \mathrm{~K}$ and an equivalence ratio of $\phi=0.82$. All gaseous mass flow rates are controlled by the mass flow meters with an accuracy of $\pm 1.5 \%$. The minimum and maximum coal particle diameters found in case METH-COAL are, respectively, $3.4 \mu \mathrm{m}$ and $98 \mu \mathrm{m}$. The measured Sauter Mean Diameter (D32) is about $15 \mu \mathrm{m}$. The distribution of particle size is available as Supplemental material.

\section{Numerical simulations}

\subsection{Mathematical modeling}

The methane-air mixture is injected conveying mono-disperse pulverized coal particles in the onedimensional axisymmetric formulation. The similarity approach is employed by searching for similar solutions of both gaseous and solid phases balance equations in the vicinity of the central axis. The similarity analysis leads to solutions of the form: $u_{g}=x U_{g}(y), v_{g}=v_{g}(y), T_{g}=$ $T_{g}(y), \rho_{g}=\rho_{g}(y), Y_{k}=Y_{k}(y), k=1, \ldots, K, u_{s}=$ $x U_{s}(y), \quad v_{s}=v_{s}(y), \quad T_{s}=T_{s}(y), \quad \rho_{s}=\rho_{s}(y), \quad \alpha_{s}=$ $\alpha_{s}(y)$, and $Y_{s d r y}=Y_{s d r y}(y)$. The superscript $g$ represents gaseous phase and the superscript $s$ the solid phase. $\rho$ is density, $u$ and $v$ the radial and axial velocities, respectively, $T$ temperature. $Y_{k}$ is $k$ th species mass fraction, $\alpha_{s}$ particles volume fraction, and $Y_{s d r y}$ dry coal mass fraction. $U_{g}$ and $U_{s}$, respectively, describe the $y$-dependence of the transverse velocities $u_{g}$ and $u_{s}$. Assuming a constant radial pressure-gradient, $J$ describes $J=-\frac{1}{x} \frac{\partial p}{\partial x}$, and is considered constant along the axial coordinate: $\partial J / \partial y=0 . f_{x}$ and $f_{y}$ are the drag forces in $x$ and $y$ directions. The parameter $j$ corresponds to 0 and 1 for two-dimensional and axisymmetric configurations, respectively. The governing equations, which describe the flow conservation of gas and solid phases, can be written in the following form:

$$
\begin{aligned}
& \frac{\partial \rho_{g}}{\partial t}+(1+j) \rho_{g} U_{g}+\frac{\partial \rho_{g} v_{g}}{\partial y}=n \dot{m}_{s} \\
& \rho_{g} \frac{\partial Y_{k}}{\partial t}+\rho_{g} v_{g} \frac{\partial Y_{k}}{\partial y}=-\frac{\partial}{\partial y}\left(\rho_{g} Y_{k} V_{k y}\right) \\
& \quad+W_{k} \dot{\omega}_{k}+n \dot{m}_{s}\left(\gamma_{s k}-Y_{k}\right), \quad k=1, \ldots, K \\
& \rho_{g} \frac{\partial u_{g}}{\partial t}+\rho_{g} U_{g}^{2}+\rho_{g} v_{g} \frac{\partial U_{g}}{\partial y} \\
& \quad=J+\frac{\partial}{\partial y}\left(\mu_{g} \frac{\partial U_{g}}{\partial y}\right)+n \dot{m}_{s}\left(U_{s}-U_{g}\right)-n f_{x}
\end{aligned}
$$




$$
\begin{aligned}
& \rho_{g} \frac{\partial h_{g}}{\partial t}+\rho_{g} v_{g} \frac{\partial h_{g}}{\partial y}=\frac{\partial}{\partial y}\left(\lambda_{g} \frac{\partial T_{g}}{\partial y}\right) \\
& -\frac{\partial}{\partial y}\left(\sum_{k=1}^{K}\left(\rho_{g} Y_{k} V_{k y} h_{k}\right)\right)+n \dot{m}_{s} \sum_{k=1}^{K}\left(\gamma_{s k} h_{k}\left(T_{s}\right)\right. \\
& \left.-Y_{k} h_{k}\left(T_{g}\right)\right)-n \dot{q}-\dot{q}_{R} \\
& \alpha_{s} \frac{\partial \rho_{s}}{\partial t}+\alpha_{s} v_{s} \frac{\partial \rho_{s}}{\partial y}=-n \dot{m}_{s} \\
& \frac{\partial \alpha_{s}}{\partial t}+(1+j) \alpha_{s} U_{s}+\frac{\partial\left(\alpha_{s} v_{s}\right)}{\partial y}=0 \\
& \alpha_{s} \rho_{s} \frac{\partial Y_{s_{d r y}}}{\partial t}+\alpha_{s} \rho_{s} v_{s} \frac{\partial Y_{s_{d r y}}}{\partial y}=-\dot{\omega}_{s_{p y r}}+Y_{s_{d r y}} n \dot{m_{s}} \\
& \alpha_{s} \rho_{s} \frac{\partial U_{s}}{\partial t}+\alpha_{s} \rho_{s} U_{s}^{2}+\alpha_{s} \rho_{s} v_{s} \frac{\partial U_{s}}{\partial y}=n f_{x} \\
& \alpha_{s} \rho_{s} \frac{\partial v_{s}}{\partial t}+\alpha_{s} \rho_{s} v_{s} \frac{\partial v_{s}}{\partial y}=\alpha_{s} \rho_{s} g+n f_{y} \\
& \alpha_{s} \rho_{s} C_{p_{s}} \frac{\partial T_{s}}{\partial t}+\alpha_{s} \rho_{s} v_{s} C_{p_{s}} \frac{\partial T_{s}}{\partial y}=-\dot{\omega}_{s p y r} \Delta h_{p y r} \\
& \sum_{k=1}^{K} \gamma_{s k} h_{k}\left(T_{s}\right) n \dot{m}_{s}+n \dot{q}
\end{aligned}
$$

In these equations $n$ represents the particle number density given by $n=\alpha_{s} / v_{p}$, with $v_{p}$ the volume of a single particle. The mass of a particle is $m_{s}=\rho_{s} v_{p}$, and $n \dot{m}_{s}$ is the total mass devolatilization rate of particles. $V_{k y}$ is the $k$ th species diffusion velocity modeled by using mixture averaged multicomponent transport [21]. $\gamma_{s k}$ is the $k$ th species percentage of the total volatilization rate. $\dot{\omega}_{k}$ and $W_{k}$ are the $k$ th species molar production rate and molar mass, respectively. $\dot{\omega}_{s_{p y r}}$ and $\dot{\omega}_{s_{c h a r}}$ represent production rate of coal and oxidation of char, respectively. $\dot{q}$ is the heat transfer rate between the gaseous and solid phases involving convective and radiative heat transfer. The Stefan-Boltzmann model is considered for the solid phase radiation. $\dot{q}_{R}$ is radiative heat transfer from the gaseous phase to the exterior using model as in [22] including reabsorption by species such as $\mathrm{CO}_{2}, \mathrm{H}_{2} \mathrm{O}$ and $\mathrm{CO}$.

\subsection{Numerical setup}

The simulation are performed using REGATH code [18] for the strained flow flame with detailed chemistry and mixture averaged multicomponent transport. To model the gaseous combustion kinetics, we have employed the $\mathrm{H}_{2} / \mathrm{CO} / \mathrm{C}_{1}-\mathrm{C}_{4}$ mechanism USC-Mech II [20]. $\mathrm{NO}_{x}$ chemistry from GRI-Mech 3.0 [23] is considered for predictions of $\mathrm{NO}_{x}$ formation. To enable comparison with $\mathrm{CH}^{*}$ measurements, the $\mathrm{CH}^{*}$ sub-mechanisms used by Alviso et al. [19] have been also added. The total chemical mechanism contains 131 species and 916 reactions.

According to experiments, an inlet stream of methane and air characterized by an equivalence ratio $\phi=0.82$ is injected from the nozzle at a gas flow velocity equal to $1.6 \mathrm{~m} / \mathrm{s}$. The fresh gases stream is fed with coal particles. The particle velocity has been measured by PIV. PIV results show that the particle average velocity matches the gas velocity at the injector exit. A typical profile is available in Supplemental material. The diameter of injected particles corresponds to the Sauter Mean Diameter measured by microscope: $D_{s}^{0}=15 \mu \mathrm{m}$ and the particle number density (per unit volume) is estimated $n_{s}=4.54 \times 10^{10}$ particles per $\mathrm{m}^{3}$ from coal mass flow rate measurements, which leads to $\alpha_{s}=8.0 \times 10^{-5}$. The brass plate is modeled as an isothermal wall of $600 \mathrm{~K}$, which corresponds to the temperature measured during the experiment. The initial properties of coal particles used for the simulations are: $\rho_{s}=909 \mathrm{~kg} / \mathrm{m}^{3}$, and the constant pressure heat capacity $c_{p s}=1.5 \mathrm{~kJ} /(\mathrm{kg} \mathrm{K})$. The pressure is equal to one atmosphere.

The coal particle is considered dry and ashfree. We consider only the transformation of solid phase to gaseous phase, i.e. the process of pyrolysis: Coal $\Longrightarrow\left(1-v_{\text {char }}\right)$ Volatile $+v_{\text {char }}$ Char and the surface oxidation: $C h a r \Longrightarrow\left(1+v_{\mathrm{O}_{2}}\right) \mathrm{CO}_{2}$. The total mass loss rate of particle phase is given by: $\dot{m}_{s}=\left(1-v_{c h a r}\right) \dot{\omega}_{s_{p y r}}+\dot{\omega}_{s_{c h a r}}$. Coal devolatilization source term $\dot{\omega}_{s_{p y r}}$ will be either modeled by firstorder single reaction model [24] or by a 2-step model [25]. The kinetic-diffusion model [26] is used for char oxidation source term $\dot{\omega}_{s_{c h a r}}$. The parameter for single reaction model and char oxidation model are modeled as in [27], and the 2-step model parameters are taken from [7]. The heat transfer between gas and particle phase decomposed as: $n \dot{q}=$ $\dot{Q}_{\text {conv }}+\dot{Q}_{\text {rad }}$. The convective heat transfer is given by $\dot{Q}_{c o n v}=\alpha_{s} \sigma_{s} k_{c o n v}\left(T_{g}-T_{s}\right)$ where $\sigma_{s}$ is the particle surface/volume ratio, $k_{\text {conv }}$ is the heat transfer coefficient of coal particles calculated assuming a Nusselt number of 2 . The radiative heat transfer is given by $\dot{Q}_{\text {rad }}=\epsilon \alpha_{s} \sigma_{s} \sigma\left(T_{w}^{4}-T_{s}^{4}\right)$ where the radiation temperature $T_{w}$ is set as the boundary temperature in this configuration, the emissivity of coal particles $\epsilon=0.85$ is kept constant in all simulations, and $\sigma$ is the Stefan-Boltzmann constant.

\subsection{Determination of volatile compositions}

The composition of volatile matter can be obtained from pyrolysis models such as CPD (Chemical Percolation Devolatilization) model [28], FG-DVC model [29] and FLASHCHAIN model [30]. Heizprofi (HP) lignite briquettes are grinded to get pulverized coal particles employed in the experiment. In this study, its total volatile matter (TVM) composition is considered as similar to the composition of lignite coals South Beulah (SB) and Morwell (MW) identified in [2]. We use the data 
Table 1

HP, SB and MW coal properties considered for numerical simulations.

\begin{tabular}{|c|c|c|c|c|c|c|c|c|c|}
\hline \multirow[t]{2}{*}{ Coal name } & \multicolumn{4}{|c|}{ Proximate analysis (wt \%) } & \multicolumn{5}{|c|}{ Ultimate analysis (wt \%) } \\
\hline & Moisture & Ash & $\begin{array}{l}\text { Volatile } \\
\text { matter }\end{array}$ & $\begin{array}{l}\text { Fixed } \\
\text { carbon }\end{array}$ & $\overline{\mathrm{C}}$ & $\mathrm{H}$ & $\mathrm{O}$ & $\mathrm{N}$ & $\mathrm{S}$ \\
\hline $\mathrm{HP}$ & 19.0 & 4.3 & 50.6 & 45.1 & 69.0 & 5.0 & 24.7 & 0.8 & 0.5 \\
\hline SB & 18.1 & 13.7 & 38.6 & 47.7 & 71.8 & 4.7 & 19.2 & 1.4 & 2.9 \\
\hline MW & 19.6 & 2.0 & 51.5 & 46.5 & 67.4 & 5.0 & 26.8 & 0.5 & 0.3 \\
\hline
\end{tabular}

Table 2

Mass percentage of species in TVM from pyrolysis of SB and MW.

\begin{tabular}{lllllllllll}
\hline Coal name & $\mathrm{CH}_{4}$ & $\mathrm{CO}$ & $\mathrm{CO}_{2}$ & $\mathrm{H}_{2}$ & $\mathrm{H}_{2} \mathrm{O}$ & $\mathrm{C}_{2} \mathrm{H}_{4}$ & $\mathrm{C}_{2} \mathrm{H}_{6}$ & $\mathrm{C}_{3} \mathrm{H}_{6}$ & $\mathrm{C}_{3} \mathrm{H}_{8}$ & $\operatorname{tar}\left(\mathrm{C}_{6} \mathrm{H}_{6}\right)$ \\
\hline SB & 3.4 & 17 & 15 & 0.66 & 12 & 1.04 & 1.04 & 1.04 & 0.52 & 48.3 \\
MW & 4.7 & 19 & 24 & 0.64 & 15 & 0.96 & 0.96 & 0.96 & 0.48 & 33.3 \\
\hline
\end{tabular}

Table 3

Different cases studied with estimated laminar flame speed $S_{l}(\mathrm{~m} / \mathrm{s})$.

\begin{tabular}{llllll}
\hline Case & Description & TVM & $1-v_{\text {char }}$ & Devolatilization & $S_{l}$ \\
\hline A & $\dot{m}_{s}=0$ in Eqs. (1)-(4) & SB & 0.6 & 1-step & 0.388 \\
B & TVM HC considered as $\mathrm{CH}_{4}$ only & SB & 0.6 & 1-step & 0.435 \\
C & Reference case & SB & 0.6 & 1 -step & 0.425 \\
D & MW composition & MW & 0.65 & 1 -step & 0.42 \\
E & 2-step devolatilization & SB & 0.6 & 2 -step & 0.424 \\
F & $V=1.3 \mathrm{~m} / \mathrm{s}$ & SB & 0.6 & 1 -step & 0.41 \\
G & $D_{s}^{0}=30 \mu \mathrm{m}$ & SB & 0.6 & 1 -step & 0.412 \\
\hline
\end{tabular}

published in [2] obtained from the CPD model. It predicts the formation of $\mathrm{CH}_{4}, \mathrm{CO}, \mathrm{CO}_{2}, \mathrm{H}_{2}, \mathrm{H}_{2} \mathrm{O}$, $\mathrm{C}_{2} \mathrm{H}_{4}, \mathrm{C}_{2} \mathrm{H}_{6}, \mathrm{C}_{3} \mathrm{H}_{6}, \mathrm{C}_{3} \mathrm{H}_{8}$, and tar. The properties of these lignite coals: HP, SB and MW coal, are listed in Table 1. Table 2 shows the mass percentage of different volatile species of SB and MW coal.

\subsection{Numerical cases studied}

Variations of TVM composition and coal devolatilization model are explored first. Table 3 shows the different cases studied. The case $A$ corresponds to a simulation where coal oxidation and devolatilization do not impact the gaseous phase (i.e. $\dot{m}_{s}=0$ in Eqs. (1)-(4)). Flame temperature is then only impacted by the combustion of methane injected through the nozzle. Cases B, C, E, F and $\mathrm{G}$ represent the TVM composition of SB coal (Table 2). In order to analyze the influence of unburned hydrocarbons present in the volatile matter on the flame structure, they are considered in case $\mathrm{B}$ as only $\mathrm{CH}_{4}(55.34 \%)$. The heating rate of coal particles is estimated $\approx 5.10^{5} \mathrm{~K} / \mathrm{s}$ from the simulation of temperature and local velocity, leading to a TVM yield $\left(1-v_{\text {char }}\right)$ of 0.6 according to [2]. Case $\mathrm{D}$ corresponds to the TVM composition of MW coal (Table 2) with $1-v_{\text {char }}=0.65$. Cases A to D use the 1-step devolatilization model [24], whereas the 2-step devolatilization model [25] is used in case $\mathrm{E}$. Case $\mathrm{C}$ is considered as a reference case, all other cases differing by only one parameter from it. Cases $\mathrm{F}$ and $\mathrm{G}$ are parametric studies further explained in 4.5 .

\section{Results and discussion}

\subsection{Flame speed}

The laminar flame speeds of the stretched flames are estimated by using the minimum of the velocity in the reaction zone [31] and are indicated in Table 3. A variation of $9.5 \%$ is observed when the impact of coal oxidation and devolatilization on the gaseous phase is accounted for. This increase of laminar flame speed is caused by the local augmentation of the fuel/air equivalence ratio induced by the release of volatile gases.

\subsection{Temperature profiles and flame structure}

Figure 2 plots the simulated temperature profiles of gas and coal particles along the jet axis. A shift of $0.6 \mathrm{~mm}$ towards the burner exit due to a difference of $0.037 \mathrm{~m} / \mathrm{s}$ in the laminar flame speed combined with a difference of $140 \mathrm{~K}$ in the maximum temperature are also observed between cases $\mathrm{A}$ and $\mathrm{C}$. Comparing cases $\mathrm{B}$ and $\mathrm{C}$, the influence of volatile gases composition is less significant as only differences of maximum temperature and laminar flame speed of $40 \mathrm{~K}$ and $0.01 \mathrm{~m} / \mathrm{s}$, respectively. The TVM composition variation illustrated by case D shows slight differences in temperature maximum and flame front position in comparison with the reference case $\mathrm{C}$. Also the complexity of the devolatilization model (case E: two-step) does not impact significantly the maximum temperature and position predicted by case C (one-step). 

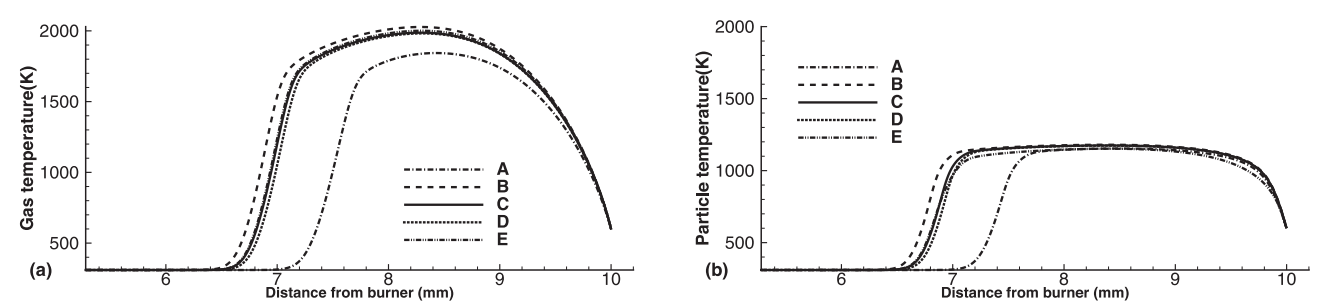

Fig. 2. Comparison of temperature profiles of (a) gas, and (b) coal particles, in cases A-E .
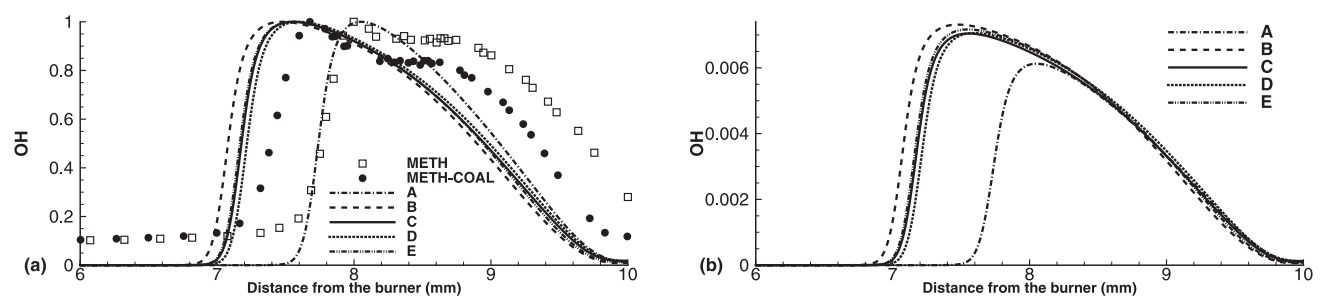

Fig. 3. Comparison of (a) normalized $\mathrm{OH}$ mole fraction profiles between experimental and numerical results, (b) absolute numerical $\mathrm{OH}$ profiles, in cases $\mathrm{A}-\mathrm{E}$.
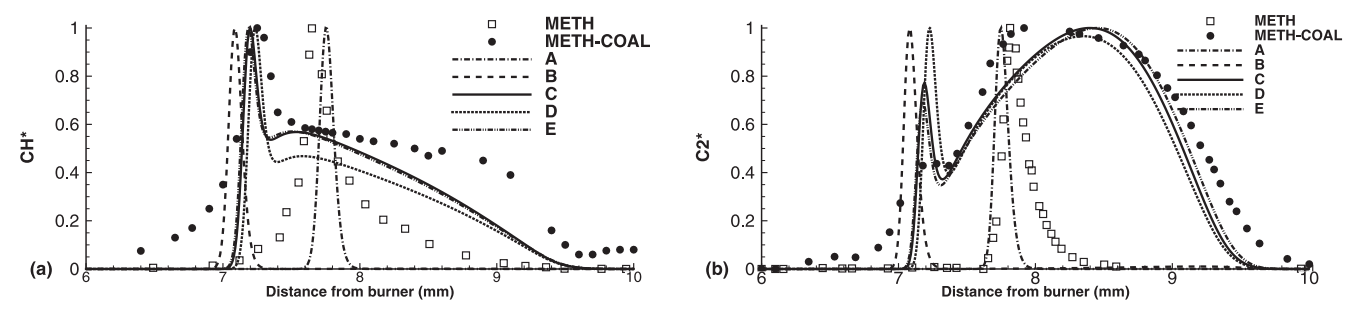

Fig. 4. Comparison of normalized (a) $\mathrm{CH}^{*}$, and (b) $\mathrm{C}_{2}^{*}$ mole fraction profiles between experimental and numerical results in cases $\mathrm{A}-\mathrm{E}$.

\subsection{Experimental and numerical profiles of $\mathrm{OH}$ radical}

The camera intensity used to measure $\mathrm{OH}$ radical varies between METH and METH-COAL cases. To avoid misleading interpretations of $\mathrm{OH}$ predictions, each numerical and experimental data is normalized between 0 and 1 for comparisons in Fig. 3a. Absolute non-normalized profiles of $\mathrm{OH}$ mole fraction are shown in Fig. 3b. The flame front position predicted by case A (where the impact of coal particles on the flow is neglected) matches well that of pure methane experiment (METH case). This result validates the numerical simulation of the gaseous phase. When coal particles are injected, the $\mathrm{OH}$ measured profiles are shifted toward the burner inlet because of the impact on the flame speed as discussed previously. This trend is quantitatively retrieved by the simulations B-E, which include coal devolatilization and oxidation. The variation of TVM composition and coal devolatilization model show slight influence in the predicted $\mathrm{OH}$ concentration.

\section{4. $\mathrm{CH}^{*}$ and $\mathrm{C2}^{*}$ spontaneous emission}

Numerical and experimental profiles of $\mathrm{CH}^{*}$ and $\mathrm{C}_{2}^{*}$ emission are normalized between 0 and 1 for comparisons in Fig. 4a and b, respectively. The peak location of $\mathrm{CH}^{*}$ measured in case METH and METH-COAL are well retrieved by simulation A and $\mathrm{B}$, respectively. Prediction the reactive layer position is however significantly improved when $\mathrm{HC}$ are included in the TVM composition (see cases $\mathrm{C}$ to E). Measurement in case METH-COAL also highlights a "prolongation" of the coal reaction zone in the burnt gases which is not observed in the methane flame. This effect is not observed in case B where the TVM unburned hydrocarbons are simplified as $\mathrm{CH}_{4}$ only. Figure 4 a shows that in cases $\mathrm{C}$ and $\mathrm{D}$, the results of $\mathrm{CH}^{*}$ emission in the hot region are well predicted. Figure $4 \mathrm{~b}$ compares normalized $\mathrm{C}_{2}^{*}$ emission intensity with numerical results. In the experiment, the intensity of $\mathrm{C}_{2}^{*}$ emission in the hot region between the coal flame front and the wall is significantly more important than the methane/air flame. This effect is predicted in cases $\mathrm{C}-\mathrm{E}$. The case 

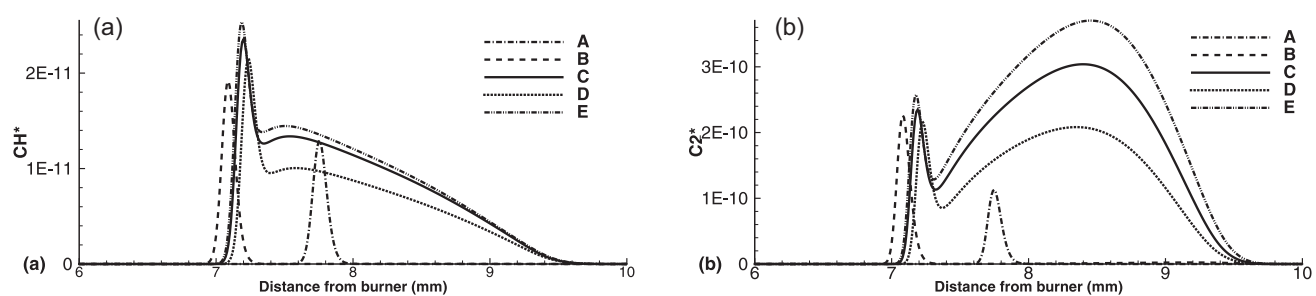

Fig. 5. Comparison of absolute numerical (a) $\mathrm{CH}^{*}$, and (b) $\mathrm{C}_{2}^{*}$ mole fraction profiles in cases A-E.
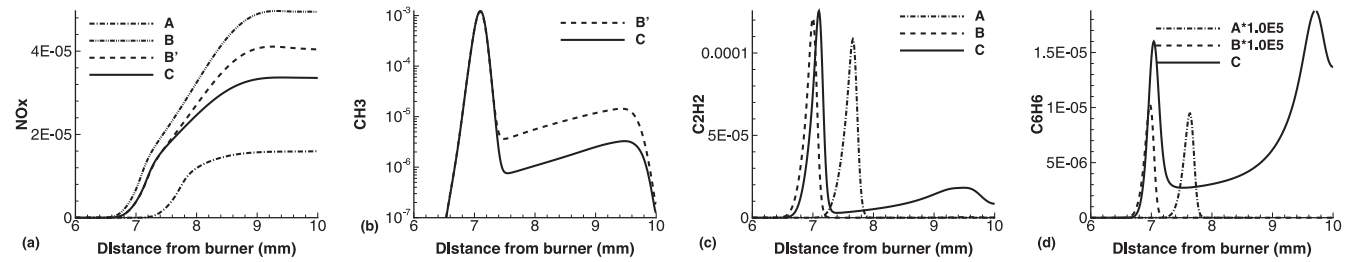

Fig. 6. Comparison of (a) $\mathrm{NO}_{x}$ mole fraction in cases A-C, (b) $\mathrm{CH}_{3}$ mole fraction in cases B' and C, (c) $\mathrm{C}_{2} \mathrm{H}_{2}$, and (d) $\mathrm{C}_{6} \mathrm{H}_{6}$ mole fraction profiles in cases $\mathrm{A}-\mathrm{C}$.
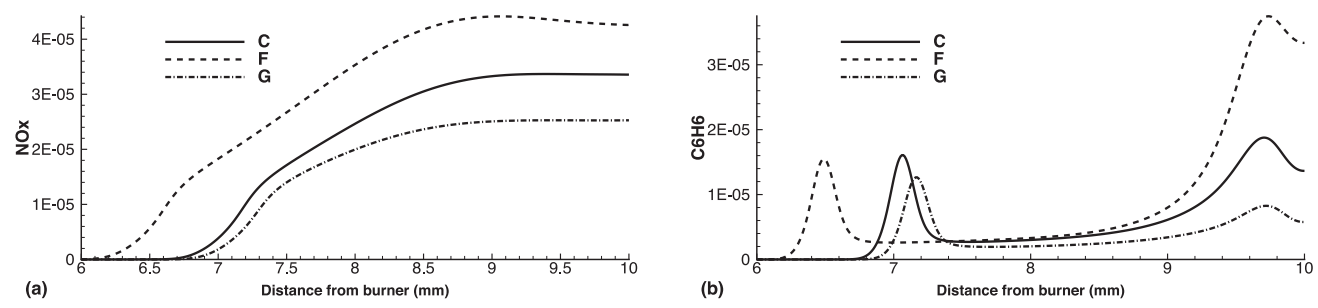

Fig. 7. Comparison of (a) $\mathrm{NO}_{x}$, (b) $\mathrm{C}_{6} \mathrm{H}_{6}$ mole fraction profiles in cases $\mathrm{C}, \mathrm{F}$ and $\mathrm{G}$.

B where organic species are considered to be only $\mathrm{CH}_{4}$ does not show similar trend in the post-flame region. Absolute non-normalized profiles of $\mathrm{CH}^{*}$ and $\mathrm{C}_{2}^{*}$ mole fraction predicted by the computation are shown in Fig. 5a and b, respectively. The maximum $\mathrm{CH}^{*}$ visible in Fig. 5a varies with the coal type. The complexity of the devolatilization model used in case $\mathrm{E}$ has a little influence on both $\mathrm{CH}^{*}$ and $\mathrm{C}_{2}^{*}$ emission.

\subsection{Pollutant formation}

Figure 6 shows the formations of $\mathrm{NO}_{x}, \mathrm{CH}_{3}$, $\mathrm{C}_{2} \mathrm{H}_{2}$ and $\mathrm{C}_{6} \mathrm{H}_{6}$. Due to the simplification of the devolatilization model, only $\mathrm{NO}_{x}$ produced by the gas-phase is discussed in this study. The $\mathrm{NO}_{x}$ production from coal-nitrogen is neglected. Comparison between cases $\mathrm{A}$ and $\mathrm{C}$ shows that the presence of volatile gases, by increasing the temperature, promotes the $\mathrm{NO}_{x}$ production. Differences observed between cases B and C predictions highlight a significant influence of the TVM composition. Case C differs from case B by the presence of heavier species in the TVM (this explains the lower burnt gases temperature observed in Fig. 2). To identify the origin of these differences, we compute an additional case B' where methane/air equivalence ratio is lowered to 0.8 to mimic the burnt gases temperature and flame speed (and position) of case $\mathrm{C}$ (see Fig. 2). Figure 6b shows that in case B', higher $\mathrm{CH}_{4}$ concentration in the TVM leads to higher concentration of $\mathrm{CH}_{i}$ radicals, which is directly involved in the promptNO reaction pathway. This explains the higher $\mathrm{NO}_{x}$ in the coal reaction zone compared to case $\mathrm{B}$.

Formation of $\mathrm{C}_{6} \mathrm{H}_{6}$ and $\mathrm{C}_{2} \mathrm{H}_{2}$, involved in the soot formation process, are influenced by the coal devolatilization, as shown in Fig. 6c and d. In particular, the presence of heavy hydrocarbons in the TVM promotes the formation of soot precursors in the burnt gases, localized between the flame front and the wall.

To study the influence of strain rate, the injection gas velocity $V$ in case $\mathrm{F}$ (Table 3 ) is set to $1.3 \mathrm{~m} / \mathrm{s}(V=1.6 \mathrm{~m} / \mathrm{s}$ in case C $)$. Numerical profiles of $\mathrm{NO}_{x}$ and $\mathrm{C}_{6} \mathrm{H}_{6}$ mole fraction are presented in Fig. $7 \mathrm{a}$ and $\mathrm{b}$, respectively. The flame front position is displaced according to the strain rate. The augmentation of residence time of coal particles induced by the decrease of strain rate explains the higher production of $\mathrm{NO}_{x}$ and $\mathrm{C}_{6} \mathrm{H}_{6}$.

In case $\mathrm{G}$ (Table 3 ), the particle number density $n$ is divided by 8 , keeping $\alpha_{s}$ constant as well as the mass flow rate of coal particles. As all the coal 
particles are represented by spheres, the particle diameter $\mathrm{D}_{s}^{0}$ is doubled. The particles with smaller size have higher heating rate and the mixing of the air and volatile reactions at the particle surfaces are more active, promoting $\mathrm{NO}_{x}$ and $\mathrm{C}_{6} \mathrm{H}_{6}$ formation, presented in Fig. 7a and b, respectively. This effect of particle size has been observed experimentally by Sung et al. [32].

\section{Conclusions}

Both experimental and numerical studies of coal/methane/air mixture combustion in a strained flow configuration have been presented. The retained configuration is a reactive flow impinging a wall surface. The coal particles burn in the hot region confined between the flame front and the stagnation plane. $\mathrm{OH}$ PLIF, $\mathrm{CH}^{*}$ and $\mathrm{C}_{2}^{*}$ chemiluminescence signals are measured in the experiments. Reacting flow equations of gaseous and solid phases have been developed and implemented in the REGATH 1-D detailed chemistry flame solver. The analysis highlights the influence of coal devolatilization on the temperature and on the $\mathrm{OH}, \mathrm{CH}^{*}$ and $\mathrm{C}_{2}^{*}$ profiles. The good agreement between experimental and numerical prediction of the reactive layer position shows that the flame speed is fairly predicted when unburned hydrocarbons presents in TVM are considered as only $\mathrm{CH}_{4}$. A significant improvement is however observed when heavy hydrocarbons are included the devolatilization gases composition. The influence of TVM composition on the pollutant formation is more pronounced, as unburned hydrocarbons significantly promotes the production of gas-phase $\mathrm{NO}_{x}$ and soot precursors. Finally parametric studies highlight the influence of strain rate and particle size on the pollutant formation.

\section{References}

[1] L. Chen, S.Z. Yong, A.F. Ghoniem, Prog. Energy Combust. 38 (2) (2012) 156-214.

[2] T. Hara, M. Muto, T. Kitano, R. Kurose, S. Komori, Combust. Flame 162 (12) (2015) 4391-4407.

[3] W.-C. Xu, A. Tomita, Fuel 66 (5) (1987) 632-636.

[4] W.-C. Xu, A. Tomita, Fuel 66 (5) (1987) 627-631.
[5] A. Molina, C.R. Shaddix, Proc. Combust. Inst. 31 (2) (2007) 1905-1912.

[6] C.R. Shaddix, A. Molina, Proc. Combust. Inst. 32 (2) (2009) 2091-2098.

[7] R. Lemaire, D. Menage, S. Menanteau, J.-L. Harion, Fuel Process. Technol. 128 (2014) 183-190.

[8] J.J. Murphy, C.R. Shaddix, Combust. Flame 144 (4) (2006) 710-729.

[9] S. Balusamy, A. Schmidt, S. Hochgreb, Exp. Fluids 54 (5) (2013) 1-14.

[10] S.M. Hwang, R. Kurose, F. Akamatsu, H. Tsuji, H. Makino, M. Katsuki, Energy Fuel 19 (2) (2005) 382-392.

[11] S. Balusamy, M. Kamal, S. Lowe, B. Tian, Y. Gao, S. Hochgreb, Exp. Fluids 56 (5) (2015) 1-16.

[12] M. Muto, H. Watanabe, R. Kurose, S. Komori, S. Balusamy, S. Hochgreb, Fuel 142 (2015) 152-163.

[13] O. Stein, G. Olenik, A. Kronenburg, et al., Flow Turbul. Combust. 90 (4) (2013) 859-884.

[14] L. Hu, L. Zhou, Y. Luo, C. Xu, Particuology 11 (2) (2013) 189-197.

[15] N. Peters, Turbulent Combustion, Cambridge University Press, 2000

[16] F. Lacas, N. Darabiha, P. Versaevel, J. Rolon, S. Candel, Symp. (Int.) Combust. 24 (1) (1992) 1523-1529.

[17] T. Daguse, T. Croonenbroek, J. Rolon, N. Darabiha, A. Soufiani, Combust. Flame 106 (3) (1996) 271-287.

[18] B. Franzelli, B. Fiorina, N. Darabiha, Proc. Combust. Inst. 34 (1) (2013) 1659-1666.

[19] D. Alviso, J. Rolon, P. Scouflaire, N. Darabiha, Fuel 153 (2015) 154-165.

[20] H. Wang, X. You, A.V. Joshi, et al., (Available at http: //ignis.usc.edu/USC_Mech_II.htm) Accessed 12 Oct. 2016.

[21] R.J. Kee, G. Dixon-Lewis, J. Warnatz, M.E. Coltrin, J.A. Miller, A Fortran Computer Code Package for the Evaluation of Gas-Phase Multicomponent Transport Properties, 1992. Gov. Pub. Sand86-8246

[22] A. Soufiani, J. Taine, Int. J. Heat Mass Transf. 40 (4) (1997) 987-991.

[23] G.P. Smith, D.M. Golden, M. Frenklach, et al., (Available at http://www.me.berkeley.edu/gri_mech/) Accessed 12 Oct. 2016.

[24] S. Badzioch, P.G.W. Hawksley, Ind. Eng. Chem. Proc. DD 9 (4) (1970) 521-530.

[25] H. Kobayashi, J. Howard, A. Sarofim, Symp. (Int.) Combust. 16 (1) (1977) 411-425.

[26] M. Baum, P. Street, Combust. Sci. Technol. 3 (5) (1971) 231-243.

[27] V. Ranade, D. Gupta, Computational Modeling of Pulverized Coal Fired Boilers, Taylor \& Francis, 2014.

[28] D.M. Grant, R.J. Pugmire, T.H. Fletcher, A.R. Kerstein, Energy Fuel 3 (2) (1989) 175-186.

[29] P.R. Solomon, D.G. Hamblen, R.M. Carangelo, M.A. Serio, G.V. Deshpande, Energy Fuel 2 (4) (1988) 405-422.

[30] S. Niksa, A.R. Kerstein, Energy Fuel 5 (5) (1991) 647-665.

[31] T. Poinsot, D. Veynante, Theoretical and Numerical Combustion, Edwards, 2005.

[32] Y.M. Sung, C.E. Moon, J.R. Kim, et al., Exp. Therm. Fluid Sci. 35 (4) (2011) 694-699. 